\title{
Soft Vaginal Capsule plus Vaginal Cream Dosage Form
}

National Cancer Institute

\section{Source}

National Cancer Institute. Soft Vaginal Capsule plus Vaginal Cream Dosage Form. NCI

Thesaurus. Code C150009.

Combination package consisting of a soft vaginal capsule and a vaginal cream. 